\title{
Dentistry and coronavirus (COVID-19) - moral decision-making
}

\author{
Paul Coulthard'
}

\section{Key points}

Examines dentistry and the global context of the current coronavirus pandemic.
Provides reasoning behind closing the author's dental school to routine treatment against the then current advice.
Debates the moral status of clinical dental healthcare personnel in balancing care for patients and personal welfare.

\begin{abstract}
The coronavirus (COVID-19) has challenged health professions and systems and has evoked different speeds of reaction and types of response around the world. The role of dental professionals in preventing the transmission of COVID-19 is critically important. While all routine dental care has been suspended in countries experiencing COVID-19 disease during the period of pandemic, the need for organised urgent care delivered by teams provided with appropriate personal protective equipment takes priority. Dental professionals can also contribute to medical care. Major and rapid reorganisation of both clinical and support services is not straightforward. Dental professionals felt a moral duty to reduce routine care for fear of spreading COVID-19 among their patients and beyond, but were understandably concerned about the financial consequences. Amidst the explosion of information available online and through social media, it is difficult to identify reliable research evidence and guidance, but moral decisions must be made.
\end{abstract}

\section{Dentistry and the global context}

The spread of coronavirus (COVID-19) has posed significant challenges for dentistry and medicine, and dental and medical schools, in all affected countries. The arrival of COVID-19 to Europe, an epicentre of the pandemic, was not unexpected having originated in Wuhan, China, in late 2019. The speed of reaction and type of response to this disease around the world have been very variable according to differing healthcare systems, economies and political ideologies.

The local government of Wuhan did not immediately recognise the significance of the new SARS-like disease reported by Dr Li Wenliang, but after some initial delay, the central government of China engaged in a rapid draconian response that worked and slowed down the explosion of COVID-19 cases. ${ }^{1}$ Measures included lockdowns and

'Queen Mary University of London, Barts and The London School of Medicine and Dentistry, Turner Street, London, E1 2AD, UK.

Correspondence to: Paul Coulthard

Email address: p.coulthard@qmul.ac.uk

Accepted 30 March 2020

https://doi.org/10.1038/s41415-020-1482-1 forced quarantines on an extraordinary scale. Collection of mobile phone location data and use of facial recognition technology to track people's movements cannot readily be replicated in other countries, and many would prioritise individual rights over this level of surveillance. China also advised that all healthcare workers use personal protective equipment (PPE), similar to that previously reserved for extremely infectious pathogens such as plague and cholera. Routine dental care was suspended in January 2020 and three months later is starting to get back to normal. ${ }^{2}$ Emergency dental care was provided with advice on strict personal protection and measures to reduce and avoid production of droplets and aerosols, use of high-volume aspiration, and others, as had been recommended during the earlier SARS outbreak. $^{3}$

Singapore, Taiwan and Hong Kong, with close links to China, quickly embarked on measures to: (1) reduce the arrival of new cases into the community (travel restrictions); (2) specifically prevent possible transmission between known cases and the local population (quarantines); and (3) generally suppress silent transmission in the community by reducing contact between individuals (self-isolation, social distancing, heightened hygiene). The latter measure was based on the view that asymptomatic individuals are infectious. While each country had a different approach to enacting these measures, all closed down routine dental care in a similar way to China. The UK National Health Service's (NHS's) initial view was that dentists and their teams should continue to provide routine care for asymptomatic patients with no close contact history and to discourage symptomatic patients from attending. Meanwhile, many general dental practitioners (GDPs) felt uncomfortable with this advice and felt a moral duty to reduce routine care for fear of spreading the COVID-19 among their patients and beyond. They were also understandably concerned, if self-employed, about the personal financial consequences. The advice to continue with routine dental care did not seem logical given the social distancing measures that were introduced for the population by the British government. In the UK and other countries in Europe, we were rapidly beyond the 'control phase, with a recognition that we could only delay the spread of disease and needed to do so in a way that might best match our already overburdened NHS capacity.

Chinese researchers had quickly isolated the new virus and sequenced its genome so that tests could be developed to identify it. ${ }^{4}$ However, 
in the US, the multiagency bureaucratic system has been blamed for their slow response. The US Centres for Disease Control (CDC) designed its first test, but then had to wait for FDA approval, only to find that it did not work. Leadership at the White House has also been criticised for lack of early prioritisation of the COVID-19 threat. Messaging and policy have been inconsistent. There is also anxiety that individuals will be put off presenting for care until their health has deteriorated significantly because of the cost of care in the huge private sector.

Unlike the US, the UK has a national healthcare system that is free at the point of delivery for medical, although not for dental, care. However, reforms over time have resulted in a national system that is fragmented and bureaucratic. Dental professionals therefore looked to the NHS for national guidance, but also to the regions of the UK as dental services are treated differently. In doing so, they found some discrepancies. Data have been rapidly analysed to inform our understanding of the disease and develop policy, and it is therefore inevitable that policy will continuously change and might not be published at the time in a desperate system. Each country of the world has been rapidly developing policy to manage the COVID-19 epidemic, taking into account guidance from the WHO but interpreting in different ways.

\section{Occupational health}

Some believe that the rapidly escalated UK response was proportionate, while others argue that the social restrictions are not sustainable beyond a short time. How tolerable in a democracy is it to close football stadiums, restaurants, schools and universities? Government decision-making is about balancing the saving of lives with risk to the economy. It is believed that the population are likely to instinctively respond to the value of saving lives rather than the harder-to-calculate harms from economic downturn. The primary moral response is to save lives. All healthcare providers have a moral obligation to care for their patients. In dentistry, we go to great lengths to select those to join the profession who demonstrate caring characteristics, and the general public expect that of us. The 'situational judgement test' is commonly used to measure attitudes and behaviours of prospective dental professionals and those in training.

We are very familiar with occupational health issues in dentistry, such as hepatitis $B$ and hepatitis $\mathrm{C}$, and risk assessment. ${ }^{5}$ Many other professions do not have to consider such issues. The New York Times reminded the world that dentistry had the most risk of any profession in relation to COVID-19. ${ }^{6}$ However, how much risk to dental care professionals is acceptable during the COVID-19 pandemic? We were initially advised by the NHS that general dental care should continue unless patients had symptoms or close contact history, and to use routine PPE. This supposes that patients are not infectious if asymptomatic. Many regions of the world, ahead of the UK with disease spread, had a different view and quickly closed down routine dental care to all. There were publications reporting dental professionals to be at high risk of COVID-19 infection due to the close face-to-face contact. ${ }^{7}$ Studies suggesting COVID-19 may be airborne through aerosols formed during medical procedures or indirectly through saliva have been published. ${ }^{8,9}$ There was an early report of one case of COVID-19 infection in Germany with transmission through contact with an asymptomatic patient. ${ }^{10}$

We are very familiar in dentistry with the principle of universal precautions for crossinfection control based on an understanding that we may not know whether a patient has the potential for disease transmission or not. As more advanced PPE is advocated for healthcare professionals caring for COVID-19 patients, then should this level of protection be used for all patients if transmission can occur from asymptomatic patients?

\section{Moral versus evidence-based decision-making}

In my opinion, the dental team are familiar with assessing cross-infection risk but should not be placed at unnecessary risk themselves as this would be morally unacceptable. I personally became increasingly concerned that asymptomatic patients might well be infectious, and that dentists and oral surgeons were not using protection with gowns, gloves, FFP3 masks and eye protection because of lack of availability. I decided that I needed to act rather than wait for more evidence. As Dean and Director of a dental school, I decided to suspend all patient care by undergraduate and postgraduate students on 16 March 2020. Non-clinical teaching, as elsewhere at other universities, was rapidly being moved to online platforms. I had set up a small COVID-19 planning team of senior staff some time earlier who worked tirelessly to manage the fallout. Students were obviously anxious and the impact on the NHS Partner Trust was significant. My measures were contrary to the then NHS advice and so my justification was required. This was based on growing but incomplete evidence and a moral judgement.

The theory that high viral load exposure of frontline medical staff in China was implicated in the severity of disease suffered and deaths of doctors and medical students was reported in the press, but not published in the scientific literature. If this was true, then surely dentists and other members of the team would be at risk because of the high volume of patients seen and with close contact. I was anxious about the risk to my oral surgery and GDP colleagues. As President of the British Association of Oral Surgeons (BAOS), I wanted to express my concern and so published a President's Newsletter online on 16 March 2020, titled 'The Oral Surgery Response to Coronavirus Disease (COVID-19). Keep Calm and Carry On?' which included my views for routine dental care. ${ }^{11}$ This was supported by all BAOS council members and I was grateful for that. I had wrestled with publically expressing my views as they were contrary to the then official NHS advice. Was I wrong? What level of PPE was really required? Would I be responsible for economic downturn in general dental practice that would be looked back on and criticised for being disproportionate? I was also conscious that I was free to rapidly put out messages as an independent clinical academic that many in professional leadership were hampered from doing because of the bureaucratic systems in which they worked, requiring greater evidence, approvals and sign-offs. In the initial phase of a pandemic when a vaccine is not available, PPE plays a major part in control. ${ }^{12}$ It makes sense to reduce routine care and direct appropriate PPE to urgent dental care when there will inevitably be an initial shortage and distribution challenge. The BAOS went on to put out a Joint Position Statement on COVID-19 and patient care with BAOMS on 20 March 2020, whose leadership were as keen as I to get messages out for surgeons and GDPs. ${ }^{13}$ This was followed by specific recommendations for urgent care of patients during the pandemic. I am comfortable that it was morally justified to get those early messages out to start the discussion and behaviour change. I am also aware that we will look back and appreciate that the differences in time of the various speciality and regional messages were actually not so significant. 


\section{Personal protective equipment}

The WHO recommends that the general public should not wear medical masks as this may cause unnecessary cost, procurement burden and create a false sense of security that can lead to neglecting other essential measures such as hand hygiene practices. ${ }^{14}$ Furthermore, using a mask incorrectly may hamper its effectiveness to reduce the risk of transmission. The WHO also recognised that masks might be worn in some countries according to local cultural habits. They do, however, recommend that individuals with respiratory symptoms should wear a medical mask and seek medical care if experiencing fever, cough and difficulty breathing, as soon as possible. Research has shown that when a mask was used on the source, it achieved far greater levels of protection than when used by the receiver. ${ }^{15}$

The WHO recommends that healthcare workers should wear a medical mask when entering a room where patients suspected or confirmed of being infected with COVID-19 are admitted and in any situation of care provided to a suspected or confirmed case. The CDC states that, when available, respirators (instead of face masks) are preferred; they should be prioritised for situations where respiratory protection is most important and for the care of patients with pathogens requiring airborne precautions (for example, tuberculosis, measles, varicella). ${ }^{16}$ The WHO recommends the use of a particulate respirator at least as protective as a US National Institute for Occupational Safety and Health (NIOSH)-certified N95, European Union (EU) standard FFP2, or equivalent, when performing aerosol-generating procedures such as tracheal intubation, non-invasive ventilation, tracheotomy, cardiopulmonary resuscitation, manual ventilation before intubation, and bronchoscopy. ${ }^{14}$ No mention of dentistry!

Dental drills cause the formation of aerosol and splatter commonly contaminated with bacteria, viruses, fungi and blood. ${ }^{17}$ Oral surgery drills also cause aerosol in addition to splatter. ${ }^{18,19}$ Aerosols are liquid and solid particles $(<50 \mu \mathrm{m}$ diameter $)$ suspended in air for protracted periods. Splatter is a mixture of air, water and/or solid substances $(50 \mu \mathrm{m}$ to several millimetres diameter). Both are a health risk to the dental team. Regular surgical face masks used in dentistry when correctly worn and frequently changed offer around $80 \%$ filtration rate. This is good protection for elective dentistry in normal circumstances, knowing that the majority of our patients are healthy. The COVID-19 measures around 120 $\mathrm{nm}(0.12 \mu \mathrm{m})$ and aerosol particle sizes range from 3-100 $\mathrm{nm}$. The use of a FFP3 respirator offers a filtration rate of $99 \%$ of all particles measuring up to $0.6 \mu \mathrm{m} .{ }^{12}$ This information drove the moral messaging that I was keen to get out, but is of course only a part of the cross-infection control measures that should be used to safeguard dental professionals and enable them to continue with urgent care of their patients.

The Health and Safety Executive back in 2008 evaluated the protection afforded by different types of masks against influenza bioaerosols and recommended the wearing of class FFP3 disposable respirators when carrying out clinical procedures likely to generate aerosols of respiratory secretions from infected patients, such as dental drilling. They noted that it is a common misperception that regular surgical masks will provide protection against aerosols and recognised the challenges of widespread delivery of FFP3 during a pandemic. ${ }^{12}$

\section{Volunteering and redeployment}

This unprecedented period is encouraging innovation and imagination. Many members of the general public are volunteering to support the NHS. Dentists and dental nurses in hospital practice, dental foundation trainees, core trainees, clinical academics and more are experiencing deployment to new roles. Hospital buildings including my own dental hospital have undergone reconfiguration to host medical care. Oral surgeons, and oral and maxillofacial surgery colleagues, will also be engaged with continuing to provide urgent dental and facial trauma and oncology surgery. Intensive care doctors are making difficult decisions. These are extraordinary times and extremely testing times for so many. I am encouraged by the dedication shown by our profession in maintaining routine service for as long as it has and in stepping up to offer urgent dental care and more. Our dental, hygienist and therapy students have instinctively set up support and volunteering groups despite their own tremendous anxieties about their academic study, assessment, accommodation and difficulties in getting home if that is overseas. We need to support each other in our professional family, reduce patient contact, restrict the generation of aerosols and use the best PPE. We also need to look out for our own mental health and wellbeing, and that of each other.

\section{References}

1. World Health Organization. Report of the WHO - China Joint Mission on Coronavirus Disease 2019 (COVID-19). 2020. Available at https://www.who.int/docs/defaultsource/coronaviruse/who-china-joint-mission-on-covid19-final-report.pdf (accessed March 2020).

2. Meng L, Hua F, Bian Z. Coronavirus Disease 2019 (COVID-19): Emerging and Future Challenges for Dental and Oral Medicine. J Dent Res 2020; DOI: $10.1177 / 0022034$.

3. Li R W, Leung K W C, Sun F C S, Samaranayake L P. Severe Acute Respiratory Syndrome (SARS) and the GDP. Part II: Implications for GDPs. Br Dent J 2004; 197: 130-134.

4. Wu F, Zhao S, Yu B et al. A new coronavirus associated with human respiratory disease in China. Nature 2020; DOI: 10.1038/s41586-020-2008-3.

5. Moodley R, Naidoo S, Wyk J V. The prevalence of occupational health related problems in dentistry: A review of the literature. J Occup Health 2018; 60: $111-125$

6. The workers who face the greatest coronavirus risk. The New York Times (New York) 2020 March 15. Available at https://www.nytimes.com/interactive/2020/03/15/ business/economy/coronavirus-worker-risk.html (accessed March 2020).

7. Peng X, Xu X, Li Y, Cheng L, Zhou X, Ren B. Transmission routes of 2019-nCoV and controls in dental practice. Int J Oral Sci 2020; 12: 9.

8. Wax R S, Christian M D. Practical recommendations for critical care and anaesthesiology teams caring for novel coronavirus (2019-nCoV) patients. Can J Anaesth 2020; DOI: 10.1007/s12630-020-01591-x.

9. To K K, Tsang O T, Chik-Yan Yip C et al. Consistent detection of 2019 novel coronavirus in saliva. Clin Infect Dis 2020; DOI: 10.1093/cid/ciaa149.

10. Rothe C, Schunk M, Sothmann P et al. Transmission of 2019-nCoV Infection from an Asymptomatic Contact in Germany. N Engl J Med 2020; 382: 970-971.

11. Coulthard P. The Oral Surgery Response to Coronavirus Disease (COVID-19). Keep Calm and Carry On? Oral Surg 2020; DOI: 10.1111/ors.12489.

12. Health and Safety Executive. Evaluating the protection afforded by surgical masks against influenza bioaerosols: Gross protection of surgical masks compared to filtering facepiece respirators. 2008. Available at https://www. hse.gov.uk/research/rrpdf/rr619.pdf (accessed March 2020).

13. Magennis P, Coulthard P. BAOS \& BAOMS - Guidance for the care of OMFS and Oral Surgery patients where COVID is prevalent. 2020. Available at https://www. baoms.org.uk/_userfiles/pages/files/professionals/ covid_19/baos baoms covid19 postions paper final. pdf (accessed March 2020).

14. World Health Organization. Advice on the use of masks in the community, during home care and in healthcare settings in the context of the novel coronavirus (COVID-19) outbreak. 2020. Available online at https://www.who.int/publications-detail/ advice-on-the-use-of-masks-in-the-communityduring-home-care-and-in-healthcare-settings-in-thecontext-of-the-novel-coronavirus-(2019-ncov)-outbreak (accessed March 2020)

15. Diaz K T, Smaldone G C. Quantifying exposure risk: Surgical masks and respirators. Am J Infect Control 2010; 38: 501-508.

16. CDC. Strategies to Optimize PPE and Equipment. 2020. Available at https://www.cdc.gov/coronavirus/2019ncov/hcp/ppe-strategy/index.html (accessed March 2020)

17. Szymanska J. Dental bioaerosol as an occupational hazard in a dentist's workplace. Ann Agric Environ Med 2007; 14: 203-207.

18. Ishihama K, lada S, Koizumi H et al. High incidence of blood exposure due to imperceptible contaminated splatters during oral surgery. J Oral Maxillofacial Surg 2008; 66: 704-710

19. Al-Eid R A, Ramalingam S, Sundar C, Aldawsari M, Nooh N. Detection of visually imperceptible blood contamination in the oral surgical clinic using forensic luminol blood detection agent. J Int Soc Prev Community Dent 2018; 8: 327-332. 